\title{
AUTORIDAD NORMATIVA Y NORMAS DE COMPETENCIA
}

\author{
FRANCISCO LÓPEZ RUIZ \\ Dpto. Filosofía del Derecho
}

\section{Sumario:}

1. Autoridad normativa y delegación. 2. Autoridad normativa, existencia y promulgación. 3. Autoridad normativa y normas que confieren poderes. 4. Jerarquía normativa y normas de competencia.

Los sistemas jurídicos se caracterizan por ser sistemas autorregulados, regulan su forma de creación, modificación y extinción. Las normas jurídicas son válidas cuando forman parte de un ordenamiento, cuando son creadas teniendo en cuenta los propios criterios de producción de normas que el ordenamiento establece. Los criterios para juzgar la pertenencia de una norma a un ordenamiento vienen determinados por el ordenamiento mismo. Los sistemas jurídicos contienen uno o varios criterios para determinar la pertenencia de las normas jurídicas a un sistema jurídico. Estos criterios suelen incluir dos tipos de reglas: las reglas de identificación y las reglas de rechazo ${ }^{1}$.

\section{Autoridad normativa y delegación}

El concepto de autoridad descansa en una estructura básica. Un sistema de autoridad sólo puede existir si aquellos que se someten a su «jurisdicción» desisten de seguir su propio juicio sobre la deseabilidad de lo que la ley prescribe. Usando la terminología de J. Raz, puede afirmarse que un «acto de autoridad» —un acto autoritativo- es una «razón excluyente» para la acción, una razón «que derrota otras razones que vayan en sentido contrario» a la hora de tomar una decisión o realizar una acción ${ }^{2}$.

\footnotetext{
${ }^{1}$ Alchourron, C. y Bulygin, e.: Introducción a la metodología de las ciencias jurídicas y sociales, Ed. Astrea, Buenos Aires, 1975, pags. 118 y ss.

${ }^{2}$ Raz, J.: Razón Práctica y Normas, Trad. de J. Ruiz Manero, Ed. C.E.C., Madrid, 1991, pags. 219 yss.
} 
La existencia de una autoridad normativa es condición necesaria y suficiente para la existencia de un sistema jurídico. No cabe pensar un sistema jurídico en el que no exista al menos una autoridad normativa.

El concepto de autoridad normativa está ligado al sistema jurídico. Alguien es autoridad normativa en un ordenamiento jurídico. Cuando hablamos de autoridad normativa no nos referimos a cualquier tipo de autoridad sino a un específico tipo de autoridad, aquella cuya titularidad y ejercicio está gobernada por reglas. Alguien es autoridad normativa y tiene ciertos poderes o competencias si admitimos la existencia de un conjunto de prescripciones que le confieren a una persona o a un órgano ciertos poderes o facultades.

Para que una norma jurídica prescriba un determinado comportamiento se requiere que tal norma sea dictada por una autoridad normativa ${ }^{3}$. Esto implica que el sistema jurídico contiene normas que autorizan o permiten, bajo ciertas circunstancias de procedimiento, la emisión de prescripciones a ciertos individuos; tales actos «son interpretados como actos de creación o de promulgación, y los individuos en cuestión son, consecuentemente considerados como autoridad normativa en relación al sistema jurídico» ${ }^{4}$.

Entre la autoridad normativa, los actos por ella producidos y los individuos sometidos a esa autoridad hay una relación de superioridad o subordinación que puede expresarse a través del concepto normativo de competencia. Desde este punto de vista, una condición necesaria para la validez de una norma es la competencia de la autoridad que la emite: una norma es válida si, y sólo si, es promulgada por una autoridad competente. La autoridad normativa que emite las normas jurídicas no deriva su potestad de sus propias cualidades personales (carisma, tradición, en terminología de Weber) sino de las mismas reglas de competencia del sistema normativo ${ }^{5}$. En los sistemas jurídicos complejos, propios de los Estados modernos, la competencia para crear normas no se centra en una sola autoridad normativa, el propio Derecho establece nuevas autoridades normativas que pueden ser competentes para crear, a su vez, otras autoridades atribuyéndoles su ámbito de competencias.

\footnotetext{
3"Por autoridad de una prescripción entendemos el agente que da o emite la prescripción. La autoridad ordena, permite, prohibe a determinados sujetos hacer determinadas cosas en determinadas ocasiones». Cfr. Von Wrigth, E.: Norma y Acción. Una investigación lógica., Ed Tecnos, Madrid, 1979, pag. 91.

${ }^{4}$ Caracciolo, R.: El concepto de autoridad normativa. El modelo de razones para la acción. Doxa, Cuadernos de Filosofía del Derecho, $\mathrm{n}^{\circ}$ 10, Alicante, 1991. Más adelante añade: «el título para crear normas equivale aquí a facultamiento y la respectiva autoridad normativa puede denominarse autoridad legal. Sus límites, es decir, la clase de los destinatarios eventuales de las prescripciones y la clase de actos que les está permitido regular están determinados por las normas de SN que establecen la competencia o el facultamiento». Este autor, distinguirá: autoridad normativa o legal, autoridad efectiva, ligada a la eficacia y, autoridad legítima vinculada a la autoridad moral.

5"La autoridad y el poder coactivo que sostienen las reglas legales no pueden localizarse en ningún individuo o grupo de individuos, sino que ha de adscribirse al sistema, al orden legal como tal». Cfr. Ross, A.: Lógica de las normas, Ed. Tecnos, Madrid, 1971, pag. 55.
} 
De todo ello surge un complejo sistema de autoridades de distintos niveles articuladas entre sí a través de un complejo proceso de delegación.

En sentido amplio podemos entender por delegación el acto en virtud del cual una autoridad normativa superior atribuye determinadas competencias a una autoridad inferior. En un sentido más preciso por delegación se entiende, todo acto dispositivo a través del cual una autoridad normativa superior fundándose en su propia competencia para disponer acerca de una deternminada materia, atribuye a otra autoridad normativa, de orden inferior, los poderes y competencias necesarias para que disponga sobre la misma materia con las determinaciones especificadas en el acto de delegación. Toda delegación es un proceso a través del cual el delegante va limitando sus competencias en favor del «delegado».

Cada acto de delegación es un acto de limitación de las propias competencias que se trasmiten a otra persona u órgano. La delegación, supone, por tanto, una estructuración jerárquica del ordenamiento jurídico, a través de la cual, se van determinado las competencias de cada autoridad normativa. Excepción hecha, claro está, que pensemos en la existencia de un ordenamiento jurídico en el que sólo exista una autoridad normativa «X», que detenta el poder absoluto y posee todas las competencias, en cuyo caso, como es obvio, no existirán normas de competencia que autoricen la delegación en otro u otros órganos. La única norma de competencia que existiría en este caso sería aquella que indica: «»X» es competente para dictar normas en este país». « ¿Se puede concebir un ordenamiento compuesto por una sola norma de estructura? Un ordenamiento de este tipo es concebible. Generalmente se considera como tal el ordenamiento de una monarquía absoluta, en donde parece que todas las normas se pueden resumir en la siguiente: «es obligatorio todo aquello que el soberano ordene».

Un sistema jurídico, es un sistema dinámico en el que las normas que lo integran se derivan unas de otras a través de una delegación sucesiva de poder, es decir, cuando hablamos de sistema dinámico no se tiene en cuenta el contenido de las normas sino la autoridad que las ha creado: una autoridad inferior deriva su poder de una autoridad superior hasta llegar a una autoridad soberana que no tiene ninguna otra autoridad sobre sí.

La autoridad normativa puede delegarse estableciéndose una relación entre autoridad delegante y autoridad delegada. Si una autoridad jurídica A ordena a B obedecer las órdenes de $\mathrm{C}$, decimos que $\mathrm{A}$ delega en $\mathrm{C}$ su autoridad y $\mathrm{C}$ adquiere competencia o poder sobre B. Por lo tanto la norma que otorga competencia a $\mathrm{C}$ es una orden, pero no es una orden dirigida a $\mathrm{C}$ sino a otras personas (Bulygin). La

${ }^{6}$ Bobbio utiliza la expresión «normas de estructura» para referirse a las normas sobre la producción jurídica, a las normas de competencia que atribuyen poderes. «Estas normas de estructura -advierte Bobbio- se pueden considerar también como las normas para la producción jurídica, o sea, las normas que regulan los procedimientos de reglamentación jurídica». Cfr. Bobbio, N.: Teoría General del Derecho, Ed. Temis, Bogotá, 1987, pag. 159. 
autoridad normativa puede transmitirse a través de sucesivas delegaciones. Si se reconoce una primera autoridad normativa se debe reconocer también aquella otra autoridad en que la primera delega. Así la autoridad normativa «X» puede delegar en la autoridad normativa «Y», ciertas competencias en ciertas materias, a su vez, «Y» puede delegar la potestad de realizar ciertos actos en $« Z »$. «X», por tanto, ha delegado en «Y $\mathrm{Y}$ » ciertas facultades o poderes $\mathrm{y}$, a su vez «Y» puede delegar parte de sus facultades en «Z». De esta forma «X», puede, a través de sucesivas delegaciones desprenderse de alguna de sus competencias. De esta forma podemos decir que « $\mathrm{Y}$ » actúa como autoridad superior inmediata de $\langle Z »$, y que «X» actúa como superior inmediato de «Y» pero como superior remoto de «Z». De estas tres autoridades normativas y de los actos por ellas producidos diremos que forman una «cadena de subordinación» en expresión de Von Wright o, una «cadena de validez» en terminología de J. Raz.

Raz define una «cadena de validez» como: «El conjunto de todas aquellas normas tales que: 1) cada una de ellas autoriza la creación de una de las restantes excepto una que no autoriza la creación de ninguna; 2 ) la creación de cada una de ellas está autorizada por una norma del conjunto con excepción de una cuya creación no se encuentra autorizada por ninguna otra de la cadena» ${ }^{7}$.

Una «cadena de subordinación» puede entenderse como un encadenamiento de eslabones tales que la autoridad «X» ordena a la autoridad «Y» que a su vez ordene a $\ll Z »$ promulgar ciertas normas. Resulta esencial en una cadena de subordinación que cada norma de ella sea válida en relación a la anterior, es decir, con el eslabón o norma superior siguiente. «Cuando decimos que una norma puede retrotraerse a otra norma, entendemos que existe una cadena de subordinación de la que la primera norma es un miembro inferior, y la segunda, uno superior. Una norma que no puede retrotraerse a alguna otra norma no puede, por definición, ser válida con relación a ninguna otra norma. Se tratará de una norma inválida con relación a alguna norma del próximo grado superior o no será válida ni inválida, es decir, soberana» (...) «así, estamos autorizados a decir que una cadena de subordinación finita termina o se origina en una norma que es soberana o inválida» ${ }^{8}$.

Las normas se crean mediante actos humanos, llamados en la terminología de Von Wright «actos normativos» cuya característica fundamental es el de constituirse a través de actos lingüísticos consistentes en un uso «performativo»o «ilocucionario» de ciertos enunciados por parte de las autoridades normativas con el propósito de promulgar prescripciones destinadas a regular la conducta humana.

Tales actos normativos pueden ser obligatorios, permitidos, prohibidos $o$ facultativos. Estos actos están regulados por normas de orden superior en terminología de Von Wright (normas secundarias en terminología de Hart). Como el acto normativo de crear o producir una determinada norma no es el contenido de ninguna

${ }^{7}$ Raz, J.: El sistema jurídico, Ed. U.N.A.M., México, 1986, pag. 126.

${ }^{8}$ Von Wrigth, E.: Op. cit., pag. 204. 
norma de orden superior entonces, se dirá que el agente o autoridad que realiza ese acto actua como soberano o autoridad suprema (Von Wright).

El acto normativo de producción de la primera Constitución no es el contenido de ninguna otra norma de orden superior, consecuentemente el agente que realiza este acto actua como soberano o autoridad suprema. El acto normativo de la autoridad soberana no puede ser el contenido de ninguna otra norma del sistema, ya que si existiese otra norma que condicionara y limitara la función de la autoridad soberana ésta dejaría de serlo, en la medida en que por autoridad soberana se entiende, aquella que, por definición no está sujeta a normas; un soberano limitado por normas es una «contradictio in terminis». El soberano o autoridad suprema no obedece a ninguna otra persona y no está limitado jurídicamente por ningún tipo de normas. Si lo estuviera dejaría de ser soberano. Este soberano podría considerársele como el legislador originario denominándolo soberano 0 para distinguirlo del soberano legal o soberano 1. En este último supuesto sí cabría admitir ciertas limitaciones en el ejercicio de sus competencias?.

La teoría clásica del Derecho público, coloca en el vértice de su construcción el concepto de soberanía, definida como el poder supremo que no está sujeto a ningún poder superior. Por el contrario, una teoría «jurídica» del poder, como la de Kelsen, coloca en el vértice del sistema jurídico la norma fundamemtal antes que el poder soberano. En una teoría normativa rigurosa como la de Kelsen, la norma fundamental es el concepto exactamente simétrico del poder soberano.

En su formulación más radical la teoría de la autoridad soberana vendría a decir que el soberano tiene el poder indiviso e incondicionado de crear y modificar el Derecho, el titular de la soberanía sería, a su vez, el titular del poder constituyente. Como advierte M. Kriele: «Una soberanía repartida entre diversos órganos sería una contradicción en los términos, pues en tal caso los órganos supremos equivalentes jerárquicamente sólo tendrían la competencia fijada por el Derecho. Por encima de los órganos estaría entonces, en primer lugar, el orden constitucional que confiere competencias; en segundo lugar, el órgano que ha de decidir sobre un conflicto de competencias, y tercero el órgano que tiene competencia para la modificación de la Constitución. Tampoco se puede decir que el soberano posee la competencia de competencias, es decir, la competencia de asumir la competencia de otros órganos. Pues aun este tipo de competencia es una competencia y, por tanto, conferida por un orden jurídico preexistente y superior. El soberano está por encima de toda competencia: es la fuente de toda competencia» ${ }^{10}$. La autoridad soberana tiene la competencia soberana y es ella la que otorga al poder estatal sus competencias. $\mathrm{La}$

${ }^{9}$ Cfr. Garzaón Valdés, E.: Acerca de las limitaciones del soberano legal, en Sistema, no 45-46.

${ }^{10}$ Kriele., M.: Introducción a la Teoría del Estado, Ed. Depalma, Buenos Aires, 1980, pag. 68.

La autoridad soberana es la titular del poder constituyente. «El poder constituyente es el único poder soberano que existe para el Estado constitucional. Dentro del Estado constitucional no hay soberanos: sólo hay soberanos en el absolutismo». Op. cit., pag. 111. 
autoridad soberana es, por tanto, la titular del poder constituyente. El poder constituyente es el poder originario, prejurídico e ilimitado. Existe, por tanto, una diferencia sustancial entre el proceso de creación de la Constitución y el de creación del Derecho ordinario, entre el poder constituyente y los poderes por ella constituidos. Los poderes que la Constitución crea y regula están subordinados a ella. El poder constituyente tiene la competencia soberana, es decir, la posibilidad soberana de decidir a quién, cuándo y en qué medida debe otorgarse una competencia jurídica. En viurtud de esta competencia soberana, puede otorgarle cualquier competencia al Estado y también negarle cualquier competencia que crea conveniente.

El concepto de poder constituyente originario ha sido objeto de agudas críticas por parte de G. Carrió ${ }^{11}$. Para este autor «toda competencia deriva de una regla o conjunto de reglas. La idea de una competencia sin reglas es algo así como un hijo sin padres». La idea de una «competencia originaria» es «autocontradictoria» puesto que competencia o poder son términos que aluden a la existencia de normas. Se hace un uso ilegítimo de los conceptos de poder y de competencia cuando se los utiliza ien contextos en los que las normas están ausentes. Y con ello se transgreden «los límites externos del lenguaje normativo».

Sin embargo, al análisis de Carrió pueden hacérsele al menos tres tipos de críticas. $1^{\mathrm{a}}$ ) Como ha señalado Nino, aquí no existe propiamente una transgresión de los límites externos del lenguaje normativo, sino que más bien se trata de traspasar el límite interno existente entre el lenguaje normativo jurídico y el lenguaje normativo moral. «De lo que se trata es, en definitiva, de establecer cuándo está moralmente justificado dictar normas de carácter constitucional no obstante la falta de competencia jurídica para hacerlo» ${ }^{12}$. De lo que se trata en el problema de marras es, de que toda atribución de competencia jurídica en este tipo de contextos, implica un cierto compromiso moral pues, no hay justificación jurídica autónoma de actos como el de atribución de competencias al primer legislador. $2^{2}$ ) La tesis de Carrió parece descansar en la idea de que sólo y exclusivamente desde la perspectiva jurídica se puede hablar con rigor de normas, poderes y competencias. Pero estamos aquí ante una petición de principio, que sólo puede alimentarse del supuesto implícito de que el discurso jurídico es sustantivo. Nada podría decirse sobre el poder, las competencias o las normas si no es desde el discurso jurídico. Este agota el campo de análisis de conceptos como los de poder o norma. A Carrió le parece evidente que nada puede saberse del poder o de las normas a no ser através del discurso jurídico, si por saber se sobreentiende precisamente, el específico discurso jurídico y esto es concretamente lo que Carrió tendría que demostrar. $3^{\text {a }}$ ) $\mathrm{El}$ planteamiento de Carrió es claramente tributario del pensamiento kelseniano respecto a las relaciones Estado-Derecho. Como es sobradamente conocido, para

\footnotetext{
${ }^{11}$ Carrio, G.: Sobre los límites del lenguaje normativo. En: «Notas sobre Derecho y lenguaje», Ed. Abeledo Perrot, Buenos Aires, 1990.

${ }^{12}$ Nino, C. S.: La validez del Derecho, Ed. Astres, Buenos Aires, 1985, pag. 46.
} 
Kelsen Estadoy Derecho son una y la misma cosa. Desde esta perspectiva todo poder es poder jurídico, toda competencia viene atribuida por normas, consecuentemente allí donde no hay normas no hay poder. Sin embargo, la práctica se encarga de demostrarnos que alguien posee competencia jurídica originaria cuando tiene el control del aparato coactivo estatal y, sus facultades para dictar normas jurídicas no derivan de otras normas sino de normas dictadas por él mismo.

\section{Autoridad normativa, existencia y promulgación}

«La promulgación consiste en una actividad esencialmente lingüística: es el acto lingüístico mediante el cual la autoridad formula la norma y la da a conocer al sujeto normativo» ${ }^{13}$. El acto de dictar una norma - promulgación- indica el momento en que ésta comimenza a existir.

Con cierta frecuencia se suelen identificar los conceptos de validez normativa y existencia normativa, sin embargo, decir que una norma existe no equivale a decir que la misma norma es válida. Una norma puede existir y ser inválida. El caso más ilustrativo al efecto el es de una ley inconstitucional. Una ley promulgada por el legislador ordinario que vulnere claramente los preceptos constitucionales existe. como tal ley. Nadie diría que una ley inconstitucional no existe, precisamente porque existe tal ley inconstitucional hay juristas interesados en su revocación. Nadie se tomaría la molestia de instar la anulación de una ley inexistente. Este sencillo ejemplo sirve precisamente para ilustrar cómo los conceptos de exstencia y validez son distintos.

«Una norma es válida cuando existe una norma de orden superior que autoriza su creación y el acto que le dio origen es un acto legítimo». De otra parte, «si decidimos llamar legal al acto de emitir una norma cuando hay una norma que permite este acto, entonces podemos decir que la validez de una norma significa la legalidad del acto de emitir esa norma» ${ }^{14}$. La noción de validez es una noción relativa. Una norma es válida cuando lo es en relación a otra norma que permite su promulgación o existencia. Sin embargo, esto no significa que la norma promulgada sea válida si la norma que autoriza su promulgación es válida. Dadas dos normas N1 y N, la primera (N1) no obtiene su validez de la segunda (N). «La validez de una norma, en el sentido que ahora discutimos, no es la validez relativa a la validez de otra norma. Es la validez relativa a la existencia de otra norma, jerárquicamente relacionada a la primera en un determinado aspecto» ${ }^{15}$. La validez no es definida, por tanto, con relación a la validez de una norma superior sino con relación a la existencia

\footnotetext{
${ }^{13}$ Alchourron, C. y Bulygin, E.: Sobre la existencia de las normas jurídicas, Ed. CLIJS, Universidad de Carabobo, Valencia, Venezuela, 1979, pag. 29.

${ }^{14}$ Von Wrigth, E.: Op. cit., pag. 200.

${ }^{15}$ Ibidem, pag. 201.
} 
de una norma superior. Así pues una norma que no pueda ser remitida a otra norma superior o bien es inválida o bien no será ni válida ni inválida. Esta norma es llamada en terminología de Von Wright norma soberana. Toda cadena de subordinación termina o bien en una norma inválida o bien en una norma soberana. La norma que otorga competencia a una autoridad, autorizándola a dictar ciertas normas, convierte en válidas las normas dictadas por esa autoridad, pero la norma validante no tiene por qué ser válida, aunque sí tiene que existir. «Si la validez fuera una condición necesaria para la existencia de una norma, entonces ni normas inválidas ni normas soberanas podrían existir» ${ }^{16}$.

\section{Autoridad normativa y normas que confieren poderes}

En el Derecho existen normas que establecen qué hay que hacer y cómo hay que realizar ciertos actos para crear una ley, dictar una sentencia, celebrar un contrato o hacer un testamento. Sólo la existencia de tales reglas que permiten a ciertas personas u órganos realizar ciertas acciones, hacen posible, no sólo entender correctamente qué es una ley, una sentencia, un contrato o un testamento, sino también «crear» leyes, sentencias, contratos o testamentos. Este tipo de norma son habitualmente denominadas normas de competencia o reglas que confieren poderes. Tanto la competencia como la capacidad pueden considerarse como «autorizaciones» para dictar ciertas normas; unas heterónomas, en el que las crea y aquél a quien se dirigen son dos sujetos distintos, por ejemplo, un reglamento administrativo, y otras autónomas, cuando el sujeto destinatario de la noŕma es el mismo que la crea, por ejemplo, un contrato (producto de la «autonomía de la voluntad»). Todo acto jurídico válido supone el ejercicio de «poderes legales» y estos presuponen, a su vez, normas que atribuyen tales poderes.

En las normas de competencia (normas que confieren poderes) podemos distinguir los siguientes elementos: 1) la determinación de la persona u órgano titular del poder y las condiciones requeridas para su ejercicio; 2) la especificación de la clase de actos que el titular del poder puede realizar y el procedimiento a seguir a tal fin; 3) la concreción de los efectos jurídicos que tiene el acto o actos válidamente realizados.

Las normas de competencia pueden atribuir a sus destinatarios poderes de ejercicio obligatorio o facultativo. Habitualmente las normas de comptencia suelen ser permisiones combinadas con obligaciones y/o prohibiciones. Por ejemplo, en nuestro ordenamiento jurídico los Decretos Legislativos se basan en la conjunción de una norma permisiva de delegación con normas de obligación y de prohibición (art. 82 C.E.).

\footnotetext{
${ }^{16} \mathrm{Cfr}$. Alchourron, C. y Bulygin, E.: Von Wright y la Filosofía del Derecho, en: «Análisis Lógico y Derecho», Ed. C.E.C., Madrid, 1991, pag. 78.
} 
Weinberger, propone definir las normas que confieren poderes como la conjunción de las dos normas siguientes:

1. una regla de producción de normas que determina el sujeto autorizado y el procedimiento de creación de normas;

2. una regla de competencia que determina el deber o el permiso de un sujeto de realizar los actos relevantes para la creación de normas ${ }^{17}$.

Autores como Bobbio, han puesto especial énfasis en considerar a las normas de competencia como normas de segundo grado, normas secundarias por referencia a las normas primarias o de primer grado (normas que imponen deberes). Las normas de segundo grado vienen definidas «por la relación que tienen con otras normas del sistema». Lo que caracteriza a la distinción entre normas primarias y normas secundarias en todas sus acepciones es «la individualización del fenómeno, que incluso algunos consideran específico del ordenamiento jurídico, de la presencia de normas cuya existencia está justificada por el hecho de que se refieren a otras normas» ${ }^{18}$.

Hart distingue dos tipos de reglas distintas pero relacionadas entre sí: 1) las reglas primarias prescriben a los hombres que hagan $u$ omitan ciertas acciones, lo quieran o no, son, por tanto, reglas que imponen deberes. 2) Las reglas secundarias que establecen formas a través de las cuales determinados sujetos pueden identificar, crear, modificar, fiscalizar y extinguir las reglas primarias. Estas reglas no se ocupan de regular la conducta humana de una forma directa, sino que versan sobre las reglas primarias. La combinación de estos dos tipos de reglas «constituye la clave de la ciencia de la Jurisprudencia». El Derecho mismo consiste en la unión de ambos tipos de reglas.

Hart establece la diferencia existente entre los ordenamientos jurídicos propios de sociedades «primitivas» y los de las sociedades «desarrolladas» sobre la base de la anterior distinción de dos tipos de reglas distintas. En una sociedad donde sólo existiesen reglas primarias el grado de inseguirdad jurídica sería muy elevado, cualquiera podría invocar la violación de una norma primaria sin que hubiera forma de resolver si ello ha ocurrido o no. En este tipo de sociedad los procesos de cambio de las reglas jurídicas serían extremadamente lentos y se producirían por vía consuetudinaria, el ordenamiento tendría un carácter fundamentalmente estático. Por último, la falta de unos órganos y de un procedimiento institucionalizado destinado a concretar cuando una norma ha sido violada o no, podría determinar la existencia de una discusión indefinida sobre si efectivamente existió tal trasgeresión. En opinión de Hart, tales problemas se solventarían con la existencia de unas reglas secundarias que suministrarían certeza (regla de reconocimiento), dinamicidad

\footnotetext{
${ }^{17}$ Weinberger, O.: Nuove considerazioni sulla teoria della nomodinámica, en el libro: «Sistemi normativi statici e dinamici», L. Gianformaggio (Comp), Ed. Giappichelli, Torino, 1991, pag. 45.

${ }^{18}$ Bobbio, N.: Normas primarias y norms secundarias. En: «Contribución a la Teoría del Derecho», Ed. Debate, Madrid, 1990, pag. 313.
} 
(reglas de cambio), y autoridad para determinar si se han transgredido o no las reglas primarias (reglas de adjudicación).

En opinión de Hart, las reglas secundarias, que confieren poderes, se distinguen de las reglas primarias. Las primeras nos «definen la manera de realizar contratos, celebrar matrimonios u otorgar testigos válidos, no exigen que las personas actuen de modos determinados, lo quieran o no. Tales normas no imponen deberes $\mathrm{u}$ obligaciones. En lugar de ello, acuerdan a los particulares facilidades para llevar a cabo sus deseos, al otorgar potestades para crear, mediante ciertos procedimientos específicos y bajo ciertas condiciones, estructuras de facultades y deberes dentro del cuadro coercitivo del derecho» ${ }^{19}$.

Por su parte, A. Ross entiende que la competencia es un caso especial de poder. El poder existe cuando una persona es capaz de producir, por medio de sus actos, los efectos jurídicos deseados. En su opinión, las normas de competencias enuncian las condiciones necesarias para crear un nuevo acto jurídico o una nueva norma legal ${ }^{20}$. Estas condiciones se dividen usualmente en tres grupos: 1) las que prescriben qué persona (o personas) está cualificada para realizar el acto creador de la norma (competencia personal); 2) las que prescriben el procedimiento a seguir (competencia de procedimiento); y 3) las que prescriben el alcance posible de la norma creada con relación a su sujeto, situación y materia (competencia material). Para Ross, las normas de competencia son reglas constitutivas ${ }^{21}$. Este tipo de reglas «constituyen» una actividad cuya existencia es lógicamente dependiente de las reglas. Las reglas constitutivas no disciplinan una conducta sino que crean y definen una nueva forma de comportamiento haciéndolo posible. El hecho de adquirir una cosa determinada y pagar por ello un precio en dinero define una práctica y constituye un hecho institucional: la compraventa. La norma que establece la mayoría de edad en los 18 años constituye y define el estado civil de «mayor de edad». El concepto de «cuadrícula minera» es creado y definido en el art. 75 de la Ley de Minas de 1973, no preexiste a su formulación activa. Las reglas «constitutivas» suelen oponerse a las reglas prescriptivas. Desde una perspectiva iusfilosófica las reglas prescriptivas no sin, ni lógica ni ontológicamente el prius del objeto regulado, mientas que una regla «constitutiva» sí es el prius de tal objeto. Los testamentos, las leyes, los juicios, los actos administrativos. No son actos naturales ni testar, ni legislar, ni juzgar a alguien, ni resolver un expediente. Son actos jurídicos concebibles solamente como constituidos por reglas jurídicas (Ross).

Otros autores sin impugnar la distinción anterior prefieren hablar de metanormas. Las normas pueden ser distinguidas teniendo en cuenta el nivel lingüístico en el cual se sitúan: normas de primer nivel o primarias que regulan directamente el compor-

\footnotetext{
${ }^{19}$ Hart, H. L. A.: El concepto de Derecho. Ed. Abeledo Perrot, Buenos Aires, pag. 35.

20"Las reglas de competencia definen cuáles son las condiciones necesarias para crear una nueva norma legal. Si un intento de legislación no satisface estas condiciones, se dice que el resultado es inválido o nulo». Cfr. Ross, A.: Lógica de las normas, Ed. Tecnos, Madrid, 1971, pag. 93.

${ }^{21}$ Ross, A.: Op. cit., pags. 93 y 123.
} 
tamiento humano, y un segundo estrato o nivel integrado por metanormas que se refieren, de diversa manera, a las normas primarias o de primer nivel, es decir, a aquellas que tienen como objeto la conducta humana (acciones o tipos de acciones). Un tipo importante de metanormas son, desde este planteamiento, las normas de competencia: normas que confieren poderes públicos o privados (legislar, contra$\operatorname{tar})^{22}$. Para unos autores las metanormas establecen los criterios de pertenencia de las normas al ordenamiento jurídico (Jori). Para otros, las metanormas establecen los criterios de validez de los actos normativos (Guastini). En ambos casos lo que importa destacar es que las metanormas se asimilan claramente a las normas de competencia.

Entre nosotros, Hernández Marín ha sostenido que «las normas de competencia establecen una condición suficiente para que un enunciado sea jurídico», y más adelante señala: «creo que las entidades a las que las normas jurídicas de competencia atribuyen la calificación de 'válida' son enunciados, más concretamente, enunciados que procedan de un órgano determinado, que hayan sido creados con arreglo a un cierto procedimiento y que versen sobre una determinada materia. $\mathrm{O}$ dicho más claramente, el sentido de una norma jurídica de competencia es: 'Los enunciados que procedan de un órgano $\mathrm{O}$, que hayan sido creados con arreglo al procedimiento $\mathrm{P}$ y referentes a la materia $\mathrm{M}$ son válidos (esto es, jurídicos) ' ' 23 .

El Derecho puede considerarse como un conjunto sistemático de normas, entendidas como razones, que guían la conducta de los individuos. Ahora bien, esta función de guía no es realizada de la misma manera por los distintos tipos de disposiciones que integran un ordenamiento jurídico. El Derecho guía la conducta del titular de un poder o potestad, pero lo hace de forma distinta a como lo realizan las normas de mandato que imponen deberes. Las normas de competencia guían el comportamiento «pero contrariamente a las reglas que imponen deberes, ellas - las normas de competencia - proporcionan una guía indeterminada para la acción. Mientras las normas que imponen deberes determinan la conducta de manera exclusiva y excluyente, las normas de competencia no determinan por sí mismas la acción a realizar, no son por sí solas razones para la acción, son en terminología de J. Raz «razones auxiliares». «Si el agente tiene razones para obtener el resultado que la facultad o el poder le permite lograr, entonces tiene razones para ejercitarla. Si tiene razones para evitar el resultado, entonces tiene una razón para no ejercitar su facultad» ${ }^{24}$. Las normas que confieren poderes no son ellas mismas «razones completas» para la acción. «Lo que uno deba hacer cuando existe una norma que le faculta $u$ otorga una potestad depende de si uno desea o tiene razones en pro o en

\footnotetext{
${ }^{22}$ Cfr. Jori, M. y Pintore, A.: Manuale di teoria generale del Diritto, Ed. Giappichelli, Torino, 1988. En el mismo sentido Guastini, R.: Della fonti alle norme, Ed. Giappichelli, segunda edición, Torino 1992.

${ }^{23}$ Hernández Marín, R.: Teoría general del Derecho y de la ciencia jurídica, Ed. PPU, Barcelona, 1989 , pag. 162.

${ }^{24}$ Raz, J.: El concepto de Sistema Jurídico, Ed. UNAM, México, 1986, pag. 272.
} 
contra de acusar un cambio normativo relevante». El dueño de una finca rústica tiene el poder o facultad (derecho subjetivo) de pedir la indemnización, por los daños causados a su heredad, al propietario de unos perros de caza que han penetrado en su finca originando daños en su cosecha, pero el uso de esa potestad no es obligatoria por parte del dueño de la finca, puede usarla o no.

Las normas de competencia funcionan como «razones auxiliares» en el razonamiento práctico. Así, yo puedo desear determina el destino de mis bienes para después de mi muerte. Tal deseo constituye lo que Raz llama una «razón operativa». El medio para hacer eficaz ese deseo es utilizar las normas que me autorizan a hacer testamento. Tales normas constituyen en este caso las «razones auxiliares».

Las normas que dotan de competencia al legislador para legislar son normas que atribuyen poderes. Ahora bien, estas normas no constituyen la «razón operativa» (causa final) para el ejercicio de su competencia. El legislador no hace las leyes por el sólo y exlcusivo hecho de tener competencia para hacerlo, sino que ejerce su función porque tiene una «razón operativa» (un fin que considera relevante), constituyendo en este caso las normas de competencia (poderes y facultades) la «razón auxiliar», es decir el medio para alcanzar el fin.

La situación de los Tribunales es diferente a la del legislador. Existen una serie de normas que les atribuyen competencias y poderes a losjueces y tribunales, pero en este caso, a diferencia del anterior, el ejercicio de tales poderes no es facultativo sino que es obligatorio. En el caso de los jueces y tribunales estamos ante la situación en que a la vez que se atribuye un poder se impone un deber. Unidas a las normas que confieren poderes se encuentran normas que imponen el deber de utilizar ese poder en una forma determinada. Con lo cual en este caso las «razones operativas» son las normas que le imponen deberes, mientras que las «razones auxiliares» son las normas procesales que determinan la formación de una sentencia válida.

\section{Jerarquía normativa y normas de competencia}

Como se ha señalado más arriba (cfr. apartado 1), todo proceso de delegación implica la existencia de una norma que autoriza o permite la traslación de competencias, por ello, la norma habilitante ostenta la doble condición de ser una norma de competencia y, a su vez, ser jerárquicamente superior a las normas emanadas por aquel órgano o persona beneficiarios de la delegación. En este sentido, la jerarquía de una norma está determinada por su ubicación en la cadena de delegación, la norma delegante es jerárquicamente superior a la norma dictada en el ejercicio del poder delegado $^{25}$. Esto supuesto, puede afirmarse que la estructura de producción de

${ }^{25}$ Sin embargo, téngase presente que no toda obligación de dictar normas de competencia implica una obligación de delegar. La obligación de delegar implica que se posee cierta competencia, nadie puede delegar más competencia de la que posee. 
normas jurídicas se compone de un conjunto de normas de competencia estructuradas jerárquicamente.

Cada acto de delegación es un acto de limitación de las propias competencias que se transmiten a otra persona u órgano. La delegación, supone, por tanto, una estructuración jerárquica del ordenamiento jurídico, a través de la cual se van determinando las competencias de cada autoridad normativa. La jerarquía involucra una gradual limitación de la competencia ya que a medida que se va delegando el delegante va desapoderándose de parcelas de competencia en favor del órgano delegado. La norma que autoriza la delegación no puede delegar más o igual poder o competencia del que ella posee ya que si así lo hiciese el delegante dejaría de ser superior jerárquico respecto del delegado. Cuando un órgano superior atribuye un poder normativo a un órgano inferior no le atribuye un poder ilimitado, puesto que al hacerlo establece también los límites dentro de los cuales puede ser ejercido dicho poder normativo. A medida que se desciende en una cadena de normas el poder normativo está más circunscrito. El poder legislativo tiene un ámbito material sustancialmente mayor que el específico del poder reglamentario - exceptuando los casos donde existe reserva reglamentaria-, la autonomía de la voluntad de los particulares tiene, a su vez, un ámbito material más limitado aún que los dos anteriores.

Las norma de un ordenamiento no se encuentran en un mismo plano, pues hay normas superiores y normas inferiores. Las normas inferiores dependen de las superiores. Como consecuencia de la presencia de normas superiores e inferiores en un ordenamiento jurídico, éste tiene una estructura jerárquica. Las normas de un ordenamiento están dispuestas en orden jerárquico. Considérese el acto que exige el cumplimiento de un contrato, A exige la realización de la obligación contratada con $\mathrm{B}$, a esto lo llamaremos acto ejecutivo. Este acto ejecutivo es el cumplimiento de una regla de conducta derivada del contrato. Por otra parte, el cumplimiento del contrato debe ajustarse a las normas legislativas que disciplinan los contratos. En cuanto a las normas legislativas éstas deben haber sido dictadas siguiendo las normas constitucionales para la creación de leyes, Por tanto, el acto ejecutivo, del cual hemos partido, está ligado, aunque en forma mediata a las normas constitucionales que producen normas inferiores.

Si observamos mejor la estructura jerárquica del ordenamiento, advertiremos que los términos ejecución y producción son relativos. Podemos afirmar que $\mathrm{A}$ ejecuta el contrato, como tambén que tanto A como B, al estipular el contrato, han ejecutado las normas legislativas sobre los contratos, y que los órganos legislativos al dictar las leyes sobre los contratos han ejecutado las normas constitucionales sobre la materia. Por otro lado, si es cierto que las normas constitucionales producen las leyes ordinarias, y también lo es que las leyes ordinarias producen normas sobre los contratos y quienes estipulan un contrato producen el acto ejecutivo de $\mathrm{A}$, podremos observar con mayor claridad la relación existente entre producción y ejecución de normas como procesos encadenados entre sí. 
De lo anterior se sigue que entre las norma reguladoras de la creación de normas y las normas creadas conforme a ellas se establece una relación de jerarquía. «La relación entre la norma que regula la producción de otra norma, y la norma producida conforme a esa determinación, puede representarse mediante la imagen espacial de la supra y subordinación. La norma que regula la producción es una norma superior, mientras que la producida conforme a esa determinación es la norma inferior ${ }^{26}$. A juicio de Kelsen entre las normas constitucionales que regulan el procedimiento legislativo y las leyes creadas por ese procedimiento se da una relación de jerarquía, en virtud de la cual la ley resultante del proceso legislativo no puede vulnerar las prescripciones constitucionales en un doble sentido: procedimental y sustantivo ${ }^{27}$. «Si la validez de la norma inferior encuentra su fundamento en la validez de la norma superior por el hecho de que la norma inferior es producida a través del modo prescrito en la norma superior, la norma superior tiene, respecto a la inferior el carácter de norma constitucional, porque la esencia de la Constitución consiste específicamente en regular la producción normativa» ${ }^{28}$.

El ordenamiento jurídico estaría estructurado en varios niveles o estratos de normas jurídicas situados horizontalmente, estos diversos niveles estarían vertebrados entre sí por medio de un eje vertical en el que se encontrarían distintas normas de competencia.

La jerarquía normativa, en opinión de Kelsen, se manifiesta de tres formas distintas: En primer lugar, cuando la superioridad de una norma $(\mathrm{N})$ sobre otra $\left(\mathrm{N}_{1}\right)$ se debe a que el contenido de la primera es precisamente la creación de la segunda. En este caso la norma superior es una norma de competencia. En la teoría kelseniana las normas que son el fundamento de validez de otras normas son jerárquicamente superiores a las fundamentadas. Estas normas que regulan la creación de otras normas han de entenderse como «normas de competencia» que, fundamentan la validez y juridicidad de las normas jerárquicamente inferiores. En segundo lygar, cuando es el propio Derecho positivo el que establece una relación de subordinación entra las diversas «formas» de manifestación del Derecho, por ejemplo, cuando el propio Derecho positivo establece una subordinación de la «forma reglamentaria» a la «forma legal», o cuando dicha relación se instaura entra la «forma legal» y la «forma constitucional». En tercer lugar, una norma $\mathrm{N}$ es (jerárquicamente) superior a otra $\mathrm{N}_{1}$, cuando esta última no puede derogar o modificar a la primera $\mathrm{N}$, pero la segunda puede ser derogada o modificada por la primera.

En el primer caso se trata de la jerarquía lógico material mientras que en el segundo se trata de la jerarquía formal ${ }^{29}$.

\footnotetext{
${ }^{26}$ Kelsen, H.: Teoría Pura del Derecho, Ed. UNAM, México, 1983, pag. 232.

${ }^{27} \mathrm{Cfr}$. Kelsen, H.: La garantía jurisdiccional de la Constitución. La justicia constitucional, en: Escritos sobre la democracia y el socialismo», (Comp. J. Ruiz Manero), Ed. Debate, Madrid, 1988.

${ }^{28} \mathrm{Kelsen}, \mathrm{H} .:$ Teoria generale delle norme, Ed. Einaudi, Torino, 1985, pag. 435.

${ }^{29}$ De Otto, I.: Lecciones de Derecho Constitucional, Ed. Giastur, Oviedo, 1980, pags. 91 y ss. En parecido sentido se manifiesta Pizzorrusso. Este autor realiza una distinción entre jerarquía normativa y
} 
La primera se da «cuando la superioridad de una norma sobre otra se debe a que el contenido de la primera es precisamente la creación de la segunda, subordinada lógicamente a ella $»^{30}$. La norma que autoriza, permite u obliga a la creación de otra norma es una norma de competencia.

La segunda, se debe a que el propio Derecho positivo establece una relación de subordinación entra las diversas «formas» de manifestación de la norma. Es el propio derecho positivo el que realiza una jerarquización entre diversas formas normativas, leyes, decretos, órdenes ministeriales, etc. La esencia de la jerarquía formal radica en que se atribuye prioridad a una forma, sea cual sea la materia que regule. No se trata de que una clase de normas queda vinculada a la regulación de una determinada materia, sino más bien de que una materia no puede ser regulada más que bajo una determinada forma normativa, la cual podría, sin embargo, ocuparse de otras materias. Por tanto, en el caso de la jerarquía formal, lo que sucede es que el propio Derecho positivo jerarquiza las distintas «formas normativas» en función de los criterios políticos con que se han estructurado los órganos del Estado.

Además de la jerarquía formal como único criterio de ordenación de las relaciones internormavtivas puede utilizarse otro criterio distinto. Se trata del principio de competencia, en virtud del cual «el texto constitucional - por ejemplo, en nuestro ordenamiento jurídico- acota, en función de la materia, ámbitos competenciales diferentes reservados a órganos y procedimientos determinados. En virtud de ello, una ley $\mathrm{X}$ no puede modificar o derogar una ley $\mathrm{Y}$, pero no porque su rango normativo sea inferior, sino porque la Constitución le veda el acceso a las materias objeto de la ley $\mathrm{Y} »^{31}$. A través de este principio se asigna a ciertos órganos un poder normativo para que a través de determinados tipos de normas, y sólo de ellas, se regulen de manera exclusiva y excluyente unas materias precisas y concretas, de tal manera que esas normas serán las únicas que podrán regular esa materia o materias ${ }^{32}$.

Una técnica de distribución de competencias diferente, pero compatible con la anterior es la de las reservas a través de la cual se especifica que ciertas materias sólo pueden ser reguladas por una «forma normativa» (la ley) y sólo por ella, esto no implica, sin embargo, que esa «forma normativa» (la ley) no pueda regular otras materias. Lo relevante en el caso de distribución de competencias es el contenido que

jerarquía instrumental. La jerarquía instrumental se da entre las normas de producción normativa con relación al resto de las normas. «Por lo tanto, las normas sobre las fuentes pueden considerarse como jerárquicamente sobreordenadas con respecto a las otras normas, pero esta jerarquía, basada en una relación esencialmente lógica como es la de instrumentalidad, no debe confundirse con la relación jerárquica entre las disposiciones que deriva del hecho de que algunas de éstas el legislador les confiere una eficacia preeminente». Cfr. Pizzorrusso, A.: Curso de Derecho Comparado, Ed. Ariel, Barcelona, 1987, pag. 146.

${ }^{30} \mathrm{De}$ Otto, I.: Lecciones de Derecho Constitucional, Ed. Giastur, Oviedo, 1980, pags. 91 y ss.

${ }^{31}$ Iturralde Sesma, V.: Lenguaje legal y sistema jurídico. Cuestiones relativas a la aplicación de la ley, Ed. Tecnos, Madrid, 1989, pags. 105 y 106.

${ }^{32}$ Las diferencias procedimentales entre normas no crean por sí solas nuevas formas normativas. 
se atribuye a cada norma y no la forma que ésta reviste. De ahí que la invalidez en este caso se produce por motivos distintos de los de la ubicación jerárquica. Cuando las normas constitucionales establecen que la materia $\mathrm{M}$ sólo puede ser regulada por las normas $X$, ha de entenderse que ningún otro tipo de norma que sea $X$ puede regular esa materia. Si una norma $Y$ trata de regular la materia $M$, esa norma $Y$ resultará inválida por vulnerar la distribución de competencias realizada por la Constitución. No existe aquí, en sentido estricto, una colisión entre las normas Xe Y sino una violación de la Constitución por parte de la norma Y. Así en nuestra Constitución los arts. 148 y 149 establecen las materias de competencia exclusiva del Estado y de las CC. AA. Las leyes estatales no podrán contradecir lo dispuesto en las leyes de las CC. AA., y éstas no podrán contradecir lo dispuesto por las leyes estatales en sus respectivos campos delimitados por los arts. 148 y 149 de la C. E. y los Estatutos de Autonomía. En estos casos la invalidez deriva del incumplimiento de la norma que ha delimitado el campo competencial específico de cada norma, atribuyendo a cada una de ellas un ámbito material distinto.

La competencia es una relación internormativa fundada en un deber de respeto recíproco entre dos normas con ámbitos de validez materiales distintos que se expresa a través de una tercera norma, interpuesta, superior a ambas ${ }^{33}$. En el supuesto de que se dé la invasión del dominio competencial de una norma por otra no se origina una antinomia entre ambas sino una vulneración de la norma superior que realiza la distribución de competencias. La consecuencia de esto es la nulidad y, por tanto, de inaplicación de la norma inferior, que ha entrado a regular una materia que le está vedada por la norma superior delimitadora de su dominio o ámbito competencial. En este sentido la vulneración del reparto competencial entre normas pordría interpretarse como violación de la norma superior distribuidora de competen-cias entre distintas fuentes, reconduciéndose el criterio de competencia a una relación de jerarquía. La competencia no sería otra cosa que una relación de jerarquía indirecta mediatizada por una norma interpuesta que normalmente será la Constitución $^{34}$. Distribución de competencias y jerarquía formal son criterios que pueden coexistir en un mismo ordenamiento e incluso en un mismo nivel jerárquico. En la relación de jerarquía el ámbito material a regular es el mismo, mientras que en la relación de competencia el ámbito de validez material de las normas es distinto. «Mientras que en la jerarquía formal la invalidación de una norma, inferior, sólo puede producirse si hay contradicción con otra, superior, en la distribución de materias tal contrtadicción no es precisa, sino que la norma resulta inaplicable por el simple hecho de haber regulado la materia vedada. Esto es así porque en la

\footnotetext{
${ }^{33}$ Balaguer Callejón, F.: Fuentes del Derecho, Ed. Tecnos, Madrid, 1991, pags. 148 y ss.

${ }^{34}$ Balaguer Callejón, F.: Fuentes..., Op. cit., pag. 149. Cita este autor la tesis de Ruggeri para el cual el principio de competencia no tiene sustantividad propia al margen del principio de jerarquía. «Toda violación de los ámbitos competenciales positivamente establecida se convierte en una violación de la norma superior que es la que fundamenta el reparto competencial».
} 
jerarquía formal la validez o invalidez resulta directamente del rango de la norma, razón por la que se habla de fuerza activa o pasiva de las normas, mientras que en el caso de la distribución de materias resulta de las normas que la llevan a cabo estableciendo qué fuentes pueden regular la materia de que se trate» ${ }^{35}$.

Las normas que distribuyen competencias especifican las condiciones y los límites dentro de los cuales un órgano puede adoptar una decisión válida. Cuando el órgano destinatario cumple las condiciones estipuladas en la norma que realiza la distibución sus actos producirán plenos efectos jurídicos. Por el contrario, si al órgano al que se le han atribuido poderes para regular una materia concreta excede ese ámbito, la consecuencia no es otra que la nulidad de ese acto.

La norma que realiza la distibución competencial consta de dos partes, la primera la podríamos denominar «supuesto» e incluiría la determinación de un órgano o sujeto normativo al que se atribuye un poder normativo sobre unas determinadas materias. La segunda, a la que podríamos denominar «consecuencia», especifica los efectos que tiene el acto válidamente realizado.

Las normas que establecen el reparto competencial pueden ser consideradas como el tipo «standard» de reglas constitutivas («X cuenta como $Y », ~ « X$ tiene el valor de $\mathrm{Y} »$, , $\mathrm{X}$ tiene el valor de $\mathrm{Y}$ en el contexto de $\mathrm{C} »)$, así el reparto competencial establecido en el art. 148 C.E., sería un claro ejemplo de este tipo de reglas, en cuanto definen las competencias que pueden asumir las CC. AA. Igualmente es un tipo «standard» de regla constitutiva el art. 23 del Cc. que determina «los requisitos comunes para la validez de la adquisición de la nacionalidad española por opción, carta de naturaleza o residencia» (vid. ut supra, pag. 16). Tales reglas constitutivas funcionarán como reglas conceptuales y no como reglas de conducta. Las reglas constitutivas son enunciados analíticos cuya verdad depende solamente del significado del término definido.

${ }^{35}$ De Otto, I.: Derecho Constitucional, Op. cit., pag. 91.

${ }^{36} \mathrm{Cfr}$. Searle, J.: Actos de habla, Ed Cátedra, Madrid, 1987, pags. 60 y ss. Sobre el mismo tema pueden consultarse las siguientes obras: Conte, A.: Regola Costitutiva, Condizione, Antinomia, Vol. «La teoría generale del Diritto. Problemi e tendenze actuali». Estudios dedicados a N. Bobbio, Ed. Comunitá, Milán 1983.

Guastini, R.: Della fonte alle norme, Ed. Guappichelli, Torino, 1992, pags. 49 y ss.

Alarcón Cabrera, C.: Sobre el concepto y tipología de las reglas constitutivas, Anuario de Filosofía del Derecho, Tomo VIII, 1991, Madrid, pags. 273 y ss. 